\title{
Fútbol y murga. \\ El habitar de los clubes carolinos
}

\author{
Clubs in San Carlos, Maldonado, coexistence of football and murga
}

\section{Diego Alsina*}

Licenciado en Educación física. Profesor Asistente del Departamento de Educación Física y Deporte, Núcleo Cultura y Sociedad, Instituto Superior de Educación Física en el CURE, Udelar, Uruguay. Maestrando en Educación Física por el PROMEF Udelar. \·dmam1989@gmail.com http://orcid.org/0000-00029426-1994

\section{RECIBIDO: 21.8.2021}

\section{Resumen}

Existe una fuerte relación temporal y espacial entre las prácticas del fútbol y la murga en la ciudad de San Carlos, Maldonado. En la primera dimensión, se vinculan con actores locales de manera cotidiana y con actores extralocales en las temporadas de competencia, con una intensidad alternada (invernal para el fútbol y estival para la murga). La relación espacial se genera a partir de que los clubes tienen la oferta y la producción de fútbol y murga en sus sedes. El objetivo del trabajo es detectar las situaciones que expresan estos universos culturales y sociales en su compleja articulación. Definir una masculinidad hegemónica en los clubes de fútbol que comparten estas actividades se vincula a los procesos de aprendizaje de un conjunto de técnicas corporales. La forma de cantar, las relaciones entre otras masculinidades y feminidades, las jerarquías en el club, los consumos, los excesos, las sensibilidades, la vestimenta... Así se adquieren determinados elementos que dan significado a los cuerpos que habitan los clubes y que disputan y ponen a prueba la hegemonía de los saberes que también modelan sus percepciones $\mathrm{y}$ valoraciones.

Palabras clave: deporte, manifestaciones culturales, Uruguay. 


\section{Abstract}

There is a strong temporal and spatial relationship between the practices of football and murga in the city of San Carlos, Maldonado. They are linked to local actors on a daily basis, and with extra-local actors during the competition seasons, with an alternating temporal intensity (winter for football and summer for murga). The spatial relationship is generated by the fact that football clubs hold and promote both football teams and murgas in the same facilities. The objective is to detect the situations expressed by these cultural and social universes in their complex articulation and relationship. Hegemonic masculinity in the clubs where these activities take place is linked to the learning processes of a set of body techniques. The way of singing, the relationships with other masculinities and femininities; the hierarchies in the club, consumption, excesses, sensibilities, clothing ...it is in this way that certain elements are acquired, giving meaning to the bodies that inhabit these clubs, disputing and testing the hegemony of knowledge, which also shapes up perceptions and appraisals.

Keywords: sport, cultural events, Uruguay.

\section{Introducción y fundamentación}

La intención de este trabajo es aportar al estudio de aspectos centrales de la configuración identitaria uruguaya. En este análisis me permito pensar algunos elementos que aparecen en mi tesis de maestría, en la cual, mediante un trabajo etnográfico, propongo estudiar y analizar el campo de producción de masculinidades en las prácticas de fútbol y murga en el Club Colón de San Carlos. Desde el marco teórico que ofrecen los estudios socioculturales del deporte, proyecto una reflexión sobre el aspecto performativo del cuerpo, a partir de la observación participante y las entrevistas etnográficas con los y las integrantes del cotidiano de la sede y la cancha del Club y de los escenarios donde actúa la murga, lo que supone que la presencia, la percepción y la experiencia serán vividas directamente en el Club y sus prácticas; por ello pondré mi cuerpo a disposición del proceso, que irá redefiniendo y resignificando dicha percepción (Guber, 2001).

Pensar las masculinidades en el escenario de los clubes deportivos permite ingresar al terreno de las moralidades. Consecuentemente, el estudio de las moralidades se relaciona con el estudio de los deseos, las emociones, la imaginación, la razón y las fronteras permitidas y rechazadas (Archetti, 2003). Esto nos pone frente al abordaje del deporte como práctica cultural y social moderna con innegable alcance y universalidad. El aporte de las ciencias sociales, las ciencias humanas y la educación marca un punto central para el abordaje del deporte a la vez que lo constituye como una arena pública (Archetti, 1984) en la que suceden y se dirimen tensiones y situaciones de lo social. Pensar 
el deporte desde esta perspectiva implica también pensar en el proceso de constitución histórica, política e identitaria local y regional, como una trama de significados plurales y particulares a la vez.

Los mecanismos básicos de construcción de identidades se producen en la vida social mediante la puesta en escena de rituales que permiten la afirmación simbólica de un yo o un nosotros frente a un ellos. Asimismo, esta perspectiva implica una mejor comprensión de las variaciones y contradicciones del campo de la moralidad, analizar los vínculos y relaciones sociales, comprender los lugares de los actores en estas actividades, indagar los aspectos discursivos dominantes, los marginales y sus intersecciones.

La hegemonía urbana, que trasciende en algunos planos de nuestra cultura y que hoy en día sigue vigente, se engendró tras la pacificación del país, su reunificación y su modernización como nación. El deporte en este sentido se manifiesta funcional al esquema social y al proceso de deportivización; muestra un intento de aculturación, en un primer momento que podríamos denominar momento cero, en el que es más evidente; devela un choque con lo que se venía dando (juegos y otras prácticas corporales) que de alguna manera es tensionado para ser transformado forzadamente a deporte. Esta perspectiva sostiene que hay un paralelismo entre el proceso de civilización y la creación del deporte, que permite conocer cambios en el ámbito social. Lo de forzadamente tiene dos motivos: a) esa práctica correspondía en alguna medida a una tradición, en el sentido de forma/s de hacer, recordar y sentir, y b) como en toda toma de decisión que implica colectivos, en ocasiones hay acuerdos, sometimientos, que en definitiva son luchas de poder. El deporte es analizado como un hecho social, lo que permite pensarlo como una construcción que se manifiesta como expresión de la cultura, en un entender histórico y una política social, que habilita el campo de crecimiento y estudio del deporte.

El deporte, entonces, parece ser uno de los inventos modernos a los que dirigir toda nuestra atención, por ser de los más exitosos y rentables, debido a que es una actividad asociada a representaciones tales como salud, educación y disfrute, que permite liberar tensiones y estrés, y que se extiende, como se ha mencionado, a diversas esferas o espacios sociales y de esta manera configura una sociedad deportivizada (Elías y Dunning, 1986). En continuidad con el planteo de los autores, el proceso de sociogénesis lleva a la emergencia y la institucionalización de los deportes (Elías y Dunning, 1986), lo que permite hablar de la obra del deporte, de las técnicas, de las reglas, de la regularización de la práctica, de su contabilización, y hace posible entender el deporte con una lógica propia, con sus relaciones, sus dinámicas, en sus procesos de regulación de los cuerpos (Gambarotta, 2019).

En el carnaval de la época bárbara, el cuerpo actuaba con desenvoltura y desenfado, con escasez de ropa y de reglas. Se gozaba y la sociedad admitía la libertad gestual, la risa, la carcajada, el hablar fuerte en los grandes espacios, los movimientos naturales de afirmación del vigor físico y la identidad sexual del hombre y la mujer. El cuerpo se 
exhibió placenteramente y se usaron su plenitud y su fuerza. Lo lúdico era un valor socialmente estimado y el desenfado corporal era practicado incluso por los adultos. El castigo era externo (corporal), sin limitar internamente las tendencias innatas al juego y al movimiento casi perpetuo (Barrán, 1989). Era una sensibilidad desenfrenada y libre de prejuicios, que repentinamente sufrió el proceso de civilización, al igual que el deporte. La sensibilidad pasó a temer al ocio, reprimir la sexualidad, enfadarse con el juego y la fiesta, endiosar el trabajo y el ahorro, recatar el cuerpo dominado. Esta historia de la sensibilidad civilizada es la de la construcción de un orden social; se exigía y a la vez presuponía una conducta civilizada, desde las normas de urbanidad hasta el trabajo disciplinado (Barrán, 1989).

Existe una fuerte creencia de que el fútbol y la murga son prácticas culturales nacionales, y en el contexto particular del club estudiado se advierte una clara relación temporal y espacial entre ambas prácticas, que vinculan a actores locales con actores extralocales en las temporadas de competencia. La relación temporal se muestra con una intensidad alternada: invernal para el fútbol y estival para la murga. La relación espacial se basa en que los clubes tienen una oferta sincrónica de fútbol y murga en sus sedes. Esta sincronía hace necesario coordinar los momentos de ensayo murguero con los momentos de entrenamiento futbolístico. El espacio compartido, el Club Colón, involucra a los individuos como agentes, necesariamente atravesados por normas, reglas, valores e instituciones; allí se relacionan el sujeto que va a ensayar en la murga, el que juega en el equipo de fútbol o realiza alguna otra actividad en el club, y el espacio en que lo hacen.

El habitar el club, en cualquiera de estas relaciones, genera un vínculo de arraigo y sentimiento que provoca diversas dinámicas y participaciones. Este sentimiento lleva que algunas y algunos sujetos se identifiquen con el club y participen como hinchas, integrantes de la murga o del equipo de fútbol. Este habitar es comprendido en las prácticas y representaciones de los que comparten esos espacios, quienes los reconocen y resignifican. En esos espacios se generan vínculos y dinámicas sociales que permiten una apropiación social, al mismo tiempo que se presentan como un escenario crítico para el desarrollo de una experiencia específica y una sensibilidad del cuerpo que permite una configuración particular de identidades (Gorelik, 2008). Este vínculo con las identidades en ese espacio supone, por un lado, el aprendizaje de un conjunto de expresiones, técnicas corporales y formas de legitimar su posición; me refiero al aprendizaje de una determinada manera de moverse, expresarse, ubicarse en el espacio, relacionarse y mostrarse. Por otro lado, en cuanto a los significados que se dan a estas concepciones sobre el cuerpo y sus relaciones, la hegemonía se disputa en las diversas consideraciones que se hacen sobre sí mismos, las que también modelan sus percepciones y valoraciones. En consecuencia, planteo un recorrido donde desarrollar la deportivización de la murga y algunas reflexiones sobre lo que ello implica. 


\section{Carnaval en sus inicios. Carnaval, espacio mimético}

Me permito decir que el carnaval y, particularmente, las murgas vienen atravesando un proceso de deportivización. Ello se observa en el concurso (campeonato) de murgas, donde se elige un ganador a partir de la evaluación de un jurado con base en parámetros de arreglos corales, voces y musicalidad; fundamento de la categoría; textos e interpretación, y puesta en escena y movimiento escénico. La deportivización de las murgas supone profesionalidad en el sentido habitual; es decir, las categorías del concurso implican entrenar el cuerpo de determinada manera, aplicar parámetros de voces, de movimientos, de relaciones, y penalizar la impuntualidad, el cantar mal, que falte gente, que las actuaciones sean aburridas o divagantes. Hay una perspectiva de espectáculo en las notas, los versos, los arreglos, las mechas, los corazones, las sorpresas, si la murga critica los partidos políticos, a los gobiernos, al sistema capitalista... A través de una ética y estética dominante se trazan los parámetros de qué es una murga y qué es una buena murga.

Pensar la deportivización del carnaval implica pensar que las características del deporte como emprendimiento moderno viven en el carnaval. El fenómeno de deportivización permite pensar la cosificación del cuerpo, debido a que toma el cuerpo como un instrumento que puede ser manipulado, operacionalizado con el fin de lograr el mejor rendimiento (Vaz, 1999). En este sentido, Michelle Carreirão menciona una posición en la actividad deportiva, una configuración estética especial que define los usos corporales:

Este processo exige um elevado domínio sobre a esfera corporal, em que as dores e fraquezas precisam ser esquecidas, superadas, para que se possa, enfim, chegar ao objetivo final: a vitória, o recorde, a melhor marca pessoal. Mas esta é uma busca que nunca se encerra, pois a atividade esportiva procura progredir cada vez mais no sentido do desempenho, delineando formas singulares de se relacionar com o corpo. (Carreirão, 2014, p. 23)

El carnaval uruguayo, dentro de estos parámetros, supone un alto control corporal, que posibilita momentos emocionantes e inimaginables, en la medida en que este control corporal es necesario en su práctica cotidiana y en el espectáculo (Carreirão, 2014). Admiramos el vestuario, el maquillaje, las voces, las coreografías, las críticas, las letras, los entrenamientos (ensayos), el modelo de competición con un sistema de producción y de reproducción definido. Un claro ejemplo de la deportivización del arte es la posibilidad de admirar la belleza en los gestos técnicos, una belleza estética ejecutada a la perfección. Este control corporal permite ver cómo el deporte moderno — carnaval moderno- da lugar al sujeto civilizado, domesticado, dominado, controlado en sus pasiones. El carnaval como ritual se supone alejado del carnaval bárbaro mencionado más 
arriba, en el que el sujeto en su autoconservación preserva aspectos de la razón. De este modo, el carnaval sigue siendo considerado un espacio donde existen permisos especiales, diversas acciones y relaciones que tienen capacidad de controlar de manera uniforme y estable los impulsos libidinales, emocionales, espontáneos y afectivos. Supone de esta manera como en toda mímesis, una tentativa de reencuentro, de reconciliación con la naturaleza (Vaz, 2007). Así, el sujeto civilizado «Em decorrência desse processo, exigiu-se a renúncia da mimese e das relações miméticas, por serem elas típicas do humano pré-subjetivo» (Carreirão, 2014, p. 44).

Gunter Gebauer e Christoph Wulf, em Mimese na cultura: agir social, rituais e jogos, produções estéticas, procuram mostrar como a mimese, que conduz à semelhança (e não à cópia), constitui elemento importante na configuração do mundo material existente, mas também de outros construídos simbolicamente. É por meio do comportamento mimético, afirmam, que os homens se revelam diante do mundo, não com ajuda do pensamento teórico, mas sim, com a ajuda dos sentidos, portanto, de forma estética. (Carreirão, 2014, 27)

Ello supone reducir el carnaval al concurso. Que las murgas actúen para rubrear. ${ }^{1}$ Que las murgas piensen en la vestimenta y el maquillaje más allá del travestirse, de ocultar una identidad, de igualar condiciones; de las voces y la musicalidad, el teatro y la actuación más allá del disfrute por la música; que se haga murga a través del espectáculo y no por el simple hecho del cantar popular, del punto del encuentro, del escenario de posibilidades e igualdad, de la crítica política, del clamor del pueblo. Carreirão (2014), siguiendo a Adorno, plantea que el primer movimiento de la mímesis permite la preservación y la autoconservación; reconocer el peligro implica primero una renuncia del sujeto a sí mismo en un intento de camuflarse con la naturaleza. El control y la determinación subjetiva de los sujetos comprende practicar las formas de dominación. La mímesis se da en el disfrute estético, como experiencia sensible que contiene en sí misma el potencial reconciliador entre el hombre y la naturaleza, justamente a través de la experiencia de la materialización del cuerpo como órgano mimético (Carreirão, 2014).

En este sentido puedo hacer el ejercicio de aproximar a Adorno y a Benjamin con Aristóteles y Platón, que usa Michelle Carreirão para definir la mímesis; de Benjamin el aspecto positivo de la mímesis de reproducir semejanzas, de asimilar y salvaguardar la razón; de Adorno el aspecto negativo, al ser una amenaza para el sujeto debido a una

Los rubros o parámetros que se han mencionado en el texto señalan los aspectos que evalúan los jueces en el concurso oficial. Cada rubro tiene puntajes asignados y la suma de todos esos puntajes da como resultado el conjunto ganador. De esta manera, el concepto de rubrear refiere a que los conjuntos atienden todos los rubros del espectáculo, en vez de responder únicamente a la funcionalidad tradicional de las murgas en el contexto uruguayo, es decir, hacer la crítica social y ser la voz del pueblo en esta reivindicación. 
pérdida de alteridades con posibilidad de una gentil aproximación (Carreirão, 2014). Es decir, en esta perspectiva el carnaval es a la vez juego y determinación, y en tal sentido el comportamiento mimético es necesario para los valores y códigos de las relaciones sociales. Este comportamiento mimético es sobre todo corporal, que permite a la vez acercar y alejar el objeto del sujeto o, en otras palabras, permite semejanzas a la vez que diferencias. Por eso es necesario comprender que el puro acercamiento amenaza las alteridades y atenta contra el comportamiento mimético que permite reflexión, autoafirmación, intercambio y encuentro (Carreirão, 2014).

El antropólogo brasileño Roberto Da Matta clasifica al carnaval como un ritual, regional o nacional, que nos permite interpretar ciertos aspectos de una sociedad. Debido a que el ritual es a la vez la representación de un conjunto de gestos, acciones y expresiones, y la representación de un drama social, crea y reproduce elementos corporales, escénicos, espontáneos, simbólicos y expresivos (Carreirão, 2014). El análisis de este aspecto se nuclea en las oposiciones básicas entre secuencias de acción dramáticas elaboradas en cada ritual en compatibilidad con el mundo cotidiano. En la resignificación y conformación del espacio social promovidas por el carnaval, los barrios, las calles y cada espacio solicitado se domestican y redefinen la ciudad. El carnaval tiene un gran poder de persuasión, capaz de vislumbrar cómo un dispositivo simbólico logra articular redes sociales amplias y diferenciadas (Da Matta, 1979).

O esporte estabelece uma relação mimética com o mundo social. Ao codificar o já existente (regras, normas, movimentos etc.), cria um espaço e tempo ficcionais (mas nem por isso, não sérios) que, assim como na realidade cotidiana, têm seus padrões de ação e de movimento preestabelecidos. 0 esporte realiza então uma representação (Darstellung) da práxis social, mas sem ser a ela idêntico, gerando um produto mimético. 0 senso prático liga-se também às técnicas corporais envolvidas na prática esportiva, na medida em que são elas um desdobramento desse conhecimento da ação (conhecimento prático do corpo), a partir de um quadro codificado, previamente determinado. São essas técnicas que conferem forma ao esporte e se localizam no centro da práxis esportiva. Assim como ocorre na arte, diz Gebauer, o esporte, em sua relação mimética com a realidade cotidiana, toma a ação de forma simbólica, realizando uma comunicação que não se dá por meio do conceito, mas corporalmente (Carreirão, 2014, p. 51).

En definitiva, el proceso de deportivización del carnaval implica una ritualización de su práctica. El ritual supone un espacio de posible imitación (aspecto negativo) y otro de creación (aspecto positivo). Esto implica, por un lado, la naturaleza de los espacios de las murgas - la representación dramática al cantar, el vestirse y pintarse, ser la voz 
del pueblo, la representación de un barrio, la crítica al sistema-y, por otro, la mecanización, la materialización y la cuantificación de los gestos o modos de hacerlos. El trabajo de Michelle Carreirão, menciona al deporte como una representación social: «Neste sentido, podemos dizer que o esporte, como representação, como encenação social, como lugar do comportamento mimético, guarda em si um momento sensível e (por que não?) estético» (Carreirão, 2014, p. 50). La codificación en el carnaval se ve a través de la materialización de los gestos.

\section{Estética en la masculinidad}

En mi tesis pretendo, en particular, problematizar el campo de las masculinidades en el contexto de los clubes deportivos, específicamente con base en las particularidades en las prácticas del fútbol y la murga en el Club Colón de San Carlos. Si comprendemos lo masculino mediante una experiencia, una posición, una práctica y un efecto, estas masculinidades se materializan en un cuerpo masculino característico, en un hombre de verdad; masculinidad que mediante un acto performativo se repite como ritual que se materializa en el contexto de un cuerpo, entendido dentro un contexto cultural (Butler, 2007).

Ser varón, y varón «de verdad», implica responder a esas disposiciones que, inevitablemente, tendremos que aprender y aprehender, desde niños hasta que la muerte diga basta. Cuando hablamos de ser macho de verdad, nos referimos a que, en tendencia, nuestras sociedades (patriarcales, profundamente machistas, sexistas y homofóbicas) interpretan, adhieren, garantizan y legitiman: ser hombre es ser fuerte, vigoroso, proveedor, corajudo, viril. Esos son los atributos que históricamente incluyen a un varón, dentro del colectivo de varones (Branz, 2017).

En síntesis, el planteo del autor me permite pensar que lo masculino se materializa en diversas prácticas corporales, a partir y a través de la asimilación y repetición de actos. Adorno, en otras palabras, señala la objetividad de lo estético «[...] a partir de los análisis de hechos, problemas y estructuras de los objetos estéticos, es decir, de las obras de arte» (Adorno, 2013, p. 48). Con la misma intención, por definir el componente estético de las representaciones sociales, señala: «[...] la única vía hacia la objetividad es la composición interna de la cosa, la estructura categorial —si puedo decirlo asíque cada obra de arte presenta en sí misma» (Adorno, 2013, p. 60), particularmente en la materialización de los gestos técnicos.

Me apoyo entonces en que esta materialidad es transformada por el ingenio humano. Considerar la materialización del cuerpo supone tomar al cuerpo como pura na- 
turaleza, como organismo que tiene la posibilidad de transformarse (Carreirão y Fernández, 2017). En el contexto estudiado, esta materialidad refuerza los aspectos masculinos hegemónicos de los espacios de carnaval, donde los hombres toman alcohol, cantan bien y fuerte, exhiben sus genitales como chiste, remarcan un lugar de poder y propiedad respecto a las mujeres que van con sus compañeros a los ensayos y actuaciones en calidad de espectadoras, donde aparecen abusos y excesos que continúan en silencio. La naturalización de estos aspectos otorga un valor social por la conquista, por la exhibición, por el valor del intercambio simbólico que supone. Como en el contexto del rugby, en la tesis de Carreirão (2014), los y las murguistas viven y recrean los límites de las potencialidades del cuerpo (Carreirão y Fernández, 2017, p. 129).

Definir una estética masculina hegemónica en este espacio se vincula a los procesos de aprendizaje de un conjunto de técnicas corporales que hacen a la disciplina. Esto se refiere al aprendizaje de la forma de cantar (bien y fuerte), a cómo se comunican con otras masculinidades y feminidades, a cómo se entienden las posiciones y jerarquías dentro de los conjuntos, a los consumos, excesos, sensibilidades, la vestimenta. Además, el aspecto performativo acciona con estas características, comunes a todas las personas involucradas en estos procesos; es decir, se adquieren determinados elementos que significan los cuerpos que disputan y ponen a prueba la hegemonía de los saberes que también modelan sus percepciones y valoraciones. Los recursos utilizados como sobrevivencia o autoconservación suponen sostener los espacios y acciones mencionadas. Adorno analiza la mímesis, en la que sujeto y objeto se aproximan a través de experiencias acumuladas, esquemas de percepción y acción (Carreirão y Fernández, 2017), lo que permite describir y entender ciertos aspectos de estos espacios:

É este, ao mesmo tempo, limite e potência, natureza a ser milimetricamente dominada que leva à máxima performance, bem como à perfeição da forma. No caso pesquisado, o corpo se deixa ver como matéria necessária para a construção da obra esportiva, como pura materialidade a ser usada pelos princípios do treinamento. Sua transformação resulta de um processo doloroso, intenso e exaustivo, cheio de abdicações e de excessos. Assim como ocorre na arte, também no esporte é preciso violentar a matéria para se poder criar formas, a partir da geração do material que, segundo a análise aqui realizada, constitui-se pelos movimentos esportivos. Assim, os gestos técnicos, como material disponível para a obra esportiva, configuram-se como o vocabulário específico da linguagem do esporte. (Carreirão y Fernández, 2017, p. 133)

En el contexto del carnaval, se normalizan prácticas permitidas y legitimadas en este ambiente, donde las normas reguladoras y las acciones materializan los cuerpos. Ello permite en este sentido un hecho performativo del ser varón y del ser mujer que 
marcan los cuerpos, los delimitan, establecen sus movimientos, sus permisos, permiten entender las relaciones de poder y hasta cuándo y cómo aguantar. En definitiva, los hombres tienen determinados privilegios allí donde las relaciones de género se articulan a partir de relaciones de poder y las conductas violentas se asocian a una supuesta esencia masculina. Estos aspectos se normalizan y pasan a ser parte del accionar cotidiano, en el que a los hombres que no incurren en estas conductas violentas y de acoso se los puede catalogar como maricas, poco hombres o cagones; en el que las prácticas que conforman el cuerpo se sostienen por estructuras con un peso y una solidez históricos; en el que el género masculino se caracteriza mediante una exhibición de virilidad, de rendimiento corporal, de imposición, entre otros elementos (Connell, 1995).

El carnaval, al igual que el deporte, como ámbito social presupone haber alcanzado un grado de autonomía que permite reconocer sus usos y sus reglas, una lógica propia y la pregunta por la técnica de la obra (Gambarotta, 2019). ¿Qué es una murga? ¿Cuáles son las voces hegemónicas? ¿Cómo se dan las relaciones y los permisos dentro de los clubes? Según Adorno y Horkheimer, «la técnica de la industria cultural ha llevado solo a la estandarización y la producción en serie y ha sacrificado aquello por lo cual la lógica de la obra se diferenciaba de la lógica del sistema social» (1994, p. 166). De esta manera puedo continuar preguntándome: ¿En qué sentido la masculinidad hegemónica en el Carnaval puede ser considerada como un acto? ¿Qué implica ser hombre en este contexto? ¿Qué cuerpos son legitimados? ¿Cómo se construye la masculinidad dominante? ¿Cómo operan la posición social, la(s) identidad(es) y el contexto cultural en la producción y reproducción de esa estética masculina dominante? ¿Cómo opera la contextualización del carnaval al suponerlo despolitizado?

En la industria cultural el individuo responde a disposiciones estandarizadas y de esta manera reafirma su condición incondicionada con lo universal. En este sentido, la asimilación del componente estético universal en este espacio consiste en la repetición, que crea un escenario particular donde arte y espectáculo responden a los parámetros de la industria cultural (Adorno y Horkheimer, 1994):

Cada uno debe demostrar que se identifica sin reservas con el poder que le golpea. En la debilidad de cada uno reconoce la sociedad su propia fortaleza y le cede una parte de ella. Su falta de resistencia lo califica como miembro de confianza. De este modo es eliminada la tragedia. En otro tiempo, la oposición del individuo a la sociedad constituía su sustancia. Esta exaltaba «el valor y la libertad de ánimo frente a un enemigo poderoso, a una adversidad superior, a un problema inquietante». La liquidación de lo trágico confirma la liquidación del individuo. (Adorno y Horkheimer, 1994, p. 198) 
Estos espacios pierden su complejidad cuanto más instrumentalizada esté su práctica de producción. La deportivización del carnaval implica un fenómeno de espectacularización en las dinámicas de la vida cotidiana, en las relaciones entre individuos, en el interés mismo del espectáculo, que puede suponer una simplificación de su práctica, debido a que pierde todo carácter político en su accionar (Gambarotta, 2019).

\section{Consideraciones finales. La despolitización del carnaval}

Si la industria cultural asiste a una de las mayores consecuencias de la mercantilización mundial naciente en la modernidad (Adorno y Horkheimer, 1994), el carnaval no puede ser ajeno a este proceso. Es a través del uso de estas categorías que se pone en juego una concepción estética que delimita las técnicas corporales. Gambarotta (2019) en este punto problematiza las condiciones de producción de juicios por los cuales estas técnicas son catalogadas, precisamente en un contexto donde predomina la industria cultural.

Pues, si una de las características centrales de la industria cultural es su apropiarse del momento activo en la constitución del fenómeno, momento que tradicionalmente se le ha adjudicado al sujeto, más aún, si su lógica lleva a la producción de la más como forma de (pseudo) subjetividad, entonces la producción de un juicio particular en base a la propia «semi-expertise» puede ser percibida como un momento de disrupción de esa industria cultural. La obra de deporte contiene, entonces, una potencialidad disruptiva, politizante de las condiciones de producción establecidas, y al mismo tiempo una potencialidad estetizante, reproductora de un culto secularizado, con el fetichismo que eso entraña (Gambarotta, 2019, p. 380).

En definitiva, la deportivización del carnaval es entender este fenómeno en términos deportivos cuando antes no se entendía así, lo que modifica significativamente no solo la forma de entenderlo, sino también su práctica, para que sea «útil» a la población que lo incorpora. Sin embargo, ambas potencialidades, las políticas y las estéticas, conviven tanto en el carnaval como en el deporte; es decir, hay una tensión constante entre la posibilidad de ser un espacio para las disidencias y la crítica social y la de ser un dispositivo reproductor de hegemonías morales. Por un lado, la murga replica una espectacularización de las relaciones, de los discursos y de los usos estéticos y corporales, en particular en cuanto a las relaciones de género, el acceso y los privilegios, las prohibiciones y permisos. Sobre todo porque cada vez tiende más a la mercantilización de los espacios populares, que hoy en día se convocan más en espacios de competencia y televisación que en los espacios barriales. 
Por otro lado, la murga se consolida históricamente como un ámbito contrahegemónico donde la crítica política no es solo una característica fundante, sino también un requisito exigido por los reglamentos del concurso y la opinión pública y popular. Es un espacio que sirve de encuentro en las relaciones humanas, un espacio que guarda una intención lúdica, un espacio de libertad, de creación, de espontaneidad, espacio de inversión y de aculturación, que a su vez lo problematiza, comunica y regenera. «Ritual, arte e esporte são tipos distintos de expressão ou de representação, são formas de mimese, cada qual com seu princípio de criação do mundo» (Carreirão, 2014, p. 49). La ritualización o dramatización de las prácticas y representaciones señaladas a lo largo del texto comprende un comportamiento mimético como espacios disruptivos y sensibles en un comportamiento estético, que permiten una óptima distancia entre la técnica y la mímesis. La espectacularización del carnaval posibilita su despolitización, es decir, el entrenamiento de las técnicas necesarias para rubrear - donde comienzan a aparecer variaciones en el canto, en las notas, en la batería de los conjuntos, en el entrenamiento de técnicas teatrales y escénicas, vestuaristas contratados para confeccionar los trajes, maquilladores y otros aspectos que comprendan la especialización de los rubros- - Sin embargo, también se constituye como espacio mimético, de juego, como espacio de denuncia de las desigualdades sociales y crítica de las estructuras políticas de la coyuntura local y regional, que visibiliza los principales debates encabezados por organizaciones sociales; espacio que se constituye como lugar de resistencia a los conflictos sociales, que mediante el humor y la sátira problematiza las injusticias y las violencias.

Se hace propio por necesidad generada o posibilidad, es decir que de alguna manera es adquirido. En esta posición, entiendo que la masculinidad hegemónica se define a través de un conjunto de normas morales de comportamiento, reconocidas y sancionadas socialmente, y en constante evaluación y adaptación. Es interesante entender que estos escenarios, así como el deporte, poseen una codificación especial y la construcción de un interés específico, así como un recorrido particular de permisos y prohibiciones (Rial, 2000). Esta perspectiva de análisis nos permite pensar el carnaval como un espacio de fuga y de resistencias, escenario óptimo para problematizar ciertos esquemas de conducta, y también nos permite hacer visibles algunas de las disputas sociales.

\section{Bibliografía}

Adorno, T. W. (2013). Estética. Buenos Aires: La Cuarenta.

Adorno, T. W., y Horkheimer, M. (1994). Dialéctica de la ilustración: Fragmentos filosóficos. Madrid: Trotta.

Archetti, E. (1984). Fútbol y ethos. Buenos Aires: Facultad Latinoamericana de Ciencias Sociales. 
Archetti, E. (2003). El potrero, la pista y el ring: Las patrias del deporte argentino. México: Fondo de Cultura Económica.

Barrán, J. (1989). Historia de la sensibilidad en el Uruguay. Tomo 1: La cultura bárbara. Montevideo: Ediciones de la Banda Oriental.

Barrán, J. (1990). Historia de la sensibilidad en el Uruguay. Tomo 1: El disciplinamiento. Montevideo: Ediciones de la Banda Oriental.

Branz, J. (2017). Masculinidades y ciencias sociales: Una relación (todavía) distante. Descentrada, 1(1), e006.

Butler, J. (2007). El género en disputa: El feminismo y la subversión de la identidad. Buenos Aires: Paidós.

Carreirão, M. (2014). Esporte e estética: Um estudo com jogadoras de rúgbi (Tesis de doctorado). Universidade Federal de Santa Catarina, Florianópolis.

Carreirão, M., y Fernandez, A. (2017). Corpo/matéria, gestos/material: para pensar uma estética dos esportes. Educação, 40(1), 126-135. doi: 10.15448/19812582.2017.1.22600

Conell, R. (1995). Masculinities: Knowledge, power and social change. Berkeley: University of California Press.

Da Matta, R. (1979). Carnavais, malandros e heróis: Para uma sociologia do dilema brasileiro. Rio de Janeiro: Zahar.

Elías, N., y Dunning, E. (1986). Deporte y ocio en el proceso de la civilización. Madrid: Fondo de Cultura Económica.

Gambarotta, E. (2019). Bosquejo ilustrado sobre el deporte: Elementos para una crítica inmanente. En B. Mora (coord.), Deporte y sociedad: Encontrando el futuro de los estudios sociales y culturales sobre deporte. Montevideo: Universidad de la República.

Gorelik, A. (2008). La aldea en la ciudad: Ecos urbanos de un debate antropológico. Revista del Museo de Antropología, (1), 73-96. doi: 10.31048/ 1852.4826.v1.n0.5398.

Guber, R. (2001). La etnografía: Método, campo y reflexividad. Bogotá: Norma.

Rial, C. (2000). Rúgbi e judô: Esporte e masculinidade. Florianópolis: Paraula.

Vaz, A. (1999). Treinar o corpo, dominar a natureza: Notas para uma análise do esporte com base no treinamento corporal. Cadernos CEDES, 19(48), 89-108.

Vaz, A. (2007). Notas conceituais sobre mímesis e educação do corpo em Max Horkheimer e Theodor W. Adorno. En B. Pucci, P. Goergen, y R. Franco (orgs.). Dialética negativa, estética e educação (pp. 187-199). Campinas: Alínea. 